\title{
LA TEMPERIE EN ARAGÓN A TRAVÉS DE SUS REFRANES
}

\author{
Eduardo Lolumo García \\ Meteorólogo en Aragón Tv \\ Avda. María Zambrano, 2, 50018-Zaragoza \\ eltiempo@aragontelevision.es \\ Profesor Universidad de la Experiencia y director del curso \\ "Tiempo y clima a tu alcance" Cursos Extraordinarios, \\ Universidad de Zaragoza, \\ C/ Pedro Cerbuna, 12, 50009 Zaragoza \\ elolumo@unizar.es
}

\begin{abstract}
Resumen: El clima y el tiempo de Aragón puede ser descrito y explicado a través de refranes que a lo largo de siglos la gente del campo ha resumido a través de sus observaciones y experiencias en frases sencillas fácilmente recordables que ayudaran de alguna forma a las generaciones venideras a tener un mayor control en las predicciones del tiempo o en un mejor conocimiento del clima. Todavía hoy esos refranes de la temperie contienen la sabiduría colectiva de quien los originó, y aunque muchos de ellos carecen de la precisión científica que las ciencias del tiempo y del clima requieren, constituyen una herramienta de conocimiento básica que va mucho más allá de una rima fácil y que merecen una atención preferente y una reflexión posterior, trascendiendo creencias y supersticiones. Están basados en la experiencia, la madre de todas las ciencias.
\end{abstract}

Palabras clave: Refranes, tiempo, clima, Aragón.

\section{The climate in Aragón by way of weather sayings and proverbs}

Abstract: Climate and weather in Aragón can be described and even explained by way of the sayings or proverbs that throughout centuries country folk has used derived from their observation and experience. These are resumed in simple sayings easy to remember as a way to help future

Recibido: 25-04-2021. Aceptado: 22-07-2021. 
generations to have some 'control' in predicting weather or having a better knowledge of the climate. Today these proverbs relating to the weather contain all the collective wisdom of those who originated them. Even though many of them lack the scientific precision that present sciences regarding weather and climate require, they constitute a basic tool that goes far beyond a simple easy rhyme and deserve an attention and reflection that transcend believes and superstitions. They are based on experience, the mother of all sciences.

Keywords: Sayings, proverbs, weather, climate, Aragón.

\section{Introducción}

Este artículo pretende ser un breve estudio de cómo el refranero meteorológico puede llegar a tener una validez mucho más allá de la genialidad de un ripio fácilmente recordable y que adorna conversaciones de ascensor.

El refrán meteorológico, como cualquier otro refrán, puede surgir espontáneamente pero su razón de existir está relacionada con la propia supervivencia de una sociedad rural, agropecuaria, que dependía casi exclusivamente de cómo lo que venía del cielo afectaba al suelo. Adelantarse para prevenir y estar preparados ante cualquier contingencia desfavorable o no, cuando no se tenían los medios que disponemos actualmente, aunque hoy igualmente se siga estando pendiente del cielo y de lo que pueda traer.

Lejos de ser este artículo un artículo puramente científico como tal, no hay que perder de vista el hecho de que los refranes meteorológicos nacen de la observación y la experiencia, "madre de todas las ciencias" como decía Don Quijote de la Mancha, algo que comparten con el método científico, yendo más allá de la mera descripción y estableciendo en ocasiones predicciones basadas en repetidas experiencias y conexiones confirmadas.

Algunos serán generales, válidos para todo el mundo porque constatan alguna ley empírica, física o química, otros determinan la dinámica atmosférica en nuestras latitudes, otros hacen referencia a situaciones locales y caracterizan el comportamiento habitual de los distintos meteoros y su distribución en el tiempo, hablaremos de clima entonces, y muchos vincularán el comportamiento de la naturaleza o los cultivos con los ciclos estacionales y sus tipos de tiempo. 


\section{Metodología}

Estos refranes, frases cortas de sencilla rima, fácilmente memorizables, pasaron de boca en boca y de oído a oído de generación en generación cuando la escritura era solo patrimonio de unos pocos.

Se hace necesaria su recopilación y su análisis para que no se pierdan en el olvido y mueran con la persona que todavía los recuerda. Hay ya varios libros y artículos que señalamos en la bibliografía que han recopilado muchos de ellos y que nos han servido de base para este artículo, otros fueron en su día recogidos en colegios, otros han sido enviados por los espectadores de El Tiempo de Aragón TV espacio que edito y presento y que se cierra de forma habitual con uno de esos refranes, algunos me han sido transmitidos directamente a través del alumnado de la Universidad de la Experiencia de la Universidad de Zaragoza de todas las sedes repartidas por nuestra comunidad a lo largo de 17 años de docencia, o incluso en las numerosas charlas que nos han permitido recorrer medio Aragón hablando del tiempo y el clima, manteniéndose en esos casos la pura transmisión oral, siendo anotados, incluso, en simples servilletas de papel.

Con todos ellos tratamos de hacer una caracterización de la temperie en Aragón, entendida como todo lo que tiene lugar entre la superficie terrestre y la troposfera y relacionado con el funcionamiento del sistema climático terrestre en nuestra comunidad. No solo describiendo, también explicando y prediciendo.

En su movimiento de traslación alrededor del Sol, la Tierra se expone de distintas formas ante el astro Rey debido a la inclinación de su eje con respecto al plano por el que se mueve, lo que en las latitudes medias del planeta supone una desigual radiación solar que implica variaciones de recepción de energía que permiten el establecimiento de cuatro estaciones astronómicas bien definidas con unos tipos de tiempo característicos y muy variados, aunque no siempre coincidentes con las fechas astronómicas convenidas.

Un repaso a cómo se comportan esas cuatro estaciones en Aragón a través del refranero meteorológico, climático y de otros tipos, pueden ayudarnos a una mejor comprensión de las mismas así como del tiempo y de los climas de Aragón, apto para todos los niveles educativos. 


\section{Estudio de las estaciones astronómicas en Aragón a través del refranero}

\subsection{La primavera}

La primavera astronómica comienza cuando los rayos del sol inciden perpendicularmente en el Ecuador, aunque climáticamente se considera ya a marzo, en su totalidad, como un mes primaveral.

Glosada como la mejor estación del año (frase de Machado) y considerada como el verdadero principio del año, climáticamente se la considera como una etapa de transición entre dos estaciones, invierno y verano con tipos de tiempo muy definidos y estables, frente a la variabilidad atmosférica primaveral: "La primavera pasa ligera, al revés que el invierno que se hace eterno".

En el Valle del Ebro "su duración, basándose en la temperatura, es de unos dos meses: del 13 de marzo al 9 de mayo (57 días)" (García de Pedraza, 1985, p.80) frente a los 121 días del invierno o los 150 del verano.

Corta e irregular, la primavera en nuestras latitudes tiene su propia personalidad, precisamente en la gran variabilidad de situaciones atmosféricas que se dan en ella, sin interrupción, generando tipos de tiempo muy distintos y de presencia corta en el tiempo, con retrocesos claros a la estación invernal y adelanto, cada vez más frecuentes, al verano.

Dicha variabilidad intrínseca le viene dada por el ascenso en latitud de la corriente en chorro, el frente polar y su rosario de borrascas. Vaguadas y dorsales en altura que debido a su carácter ondulatorio dan tipos de tiempo muy distintos.

Numerosos refranes hacen referencia a esa variabilidad meteorológica que ya podemos ir encontrando en el último mes del invierno, "febrerillo el loco", y que el mes de marzo confirma si su comportamiento es el habitual y "marcea", "marzo marzuelo, un día malo y otro bueno".

Incluso dentro de un mismo día, la situación térmica puede ser ostensiblemente distinta de día y de noche: "Marzo marceador, por la noche frío y por el día calor" o "marzo marcero, un rato al sol y otro al bumero".

La oscilación térmica diaria es acusada en la primavera, especialmente en marzo y en situaciones anticiclónicas sin viento en las que el sol ya tiene un recorrido considerable en el horizonte, la luz solar va ganando a la noche a partir del equilux, y el sol calienta lo suficiente: "El sol de marzo pega como un mazo" algo que notamos más viniendo de los meses invernales. 
Pero las noches son todavía suficientemente largas como para que la energía acumulada durante el día escape a la atmósfera rápidamente si nada lo impide, especialmente en situaciones anticiclónicas y sin viento.

La continentalidad acusada de los climas de Aragón se manifiesta perfectamente en estas amplias oscilaciones térmicas diarias, especialmente en el Valle del Jiloca, el Turia o el Alfambra, valles entre 800 y 1000 m de altitud, dando amplias oscilaciones térmicas diarias.

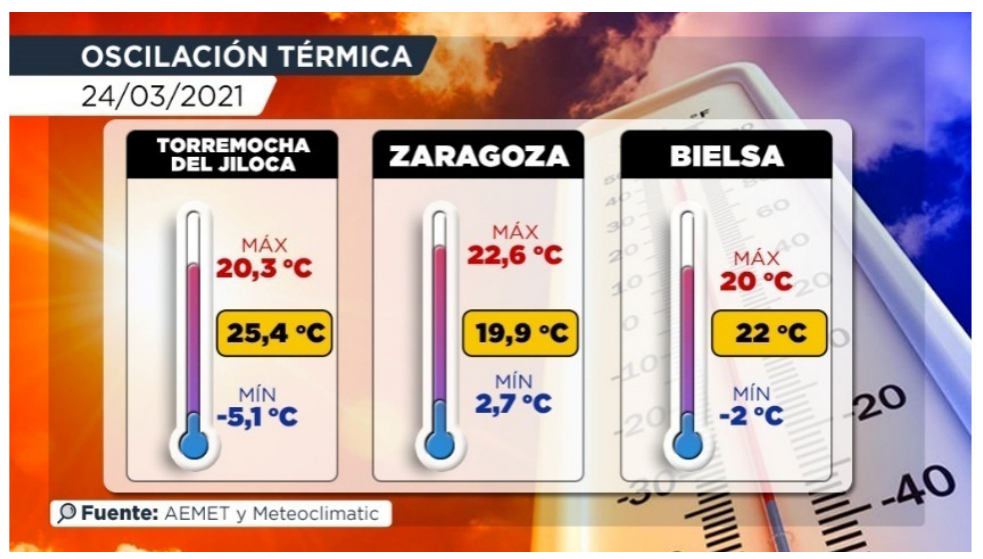

Figura 1. Oscilaciones térmicas amplias en primavera en una situación anticiclónica. Archivo Aragón Tv.

Fuente: Elaboración propia.

El frío nocturno puede sobrevenir por una advección fría polar, muy probable a principios de la estación, y tras el cese de la misma y posterior afianzamiento de las altas presiones, se pueden dar temperaturas mínimas muy bajas: con una "noche clara y estrellada habrá escarcha o rociada" (sin viento, claro) con temperaturas bajo cero, heladas de irradiación muy temidas por la gente del campo especialmente en el fondo de los valles más altos. Las heladas primaverales.

Las bajas temperaturas y las heladas son un fenómeno meteorológico habitual en el invierno, necesarias para el normal devenir de los cultivos, pero en primavera constituyen un riesgo agroclimático "en los sectores de regadío, particularmente en las zonas frutícolas, el elemento climático que representa un mayor porcentaje de pérdidas son las heladas de primavera" (Hernández, 1995, p. 378).

Comarcas frutícolas como Valdejalón, Bajo y Medio Cinca, La Litera y en especial las Comunidad de Calatayud con el propio Jalón o en valles altos como el del Ribota o el Manubles son un ejemplo de ello. 
El refranero lo tiene muy en cuenta, y los refranes agroclimáticos especialmente, fijando una fecha en el calendario, el 25 de marzo, el día de la Encarnación: "Os chelos d'a Encarnazión os zagueros son, si marzo no sale respondón”. Pero no siempre es así, y la climatología como ciencia sabe hablar de los datos medios, pero también de la probabilidad de los extremos y a veces marzo, abril e incluso mayo salen respondones (marzo y abril de 2021 han registrado numerosos días de heladas) En tan solo media hora se puede dar al traste con toda o parte de la producción en una parcela agrícola dependiendo del estado fenológico de la planta.

En esas fechas extremas de posibilidad de helada está el 23 de abril "San Chorche o laminero, que se mincha a fruita ta que no dentre en o frutero" y para algunos cultivos como la vid con despertar fenológico más tardano, todavía va más allá el riesgo: "No me digas uga en zesta sin pasar Santa Baldesca (28 de mayo)"o en el Somontano oscense, tierra de vinos: "Mientras veas Guara como a coda de una sardina, no tiens segura a viña" (coda de una sardina es la apariencia que tiene Guara cuando todavía tiene nieve en su cumbre).

Algunas vides están en zonas altas mucho más que la mayoría de los frutales y es posible que efectivamente en mayo pueda haber alguna helada que las afecte.

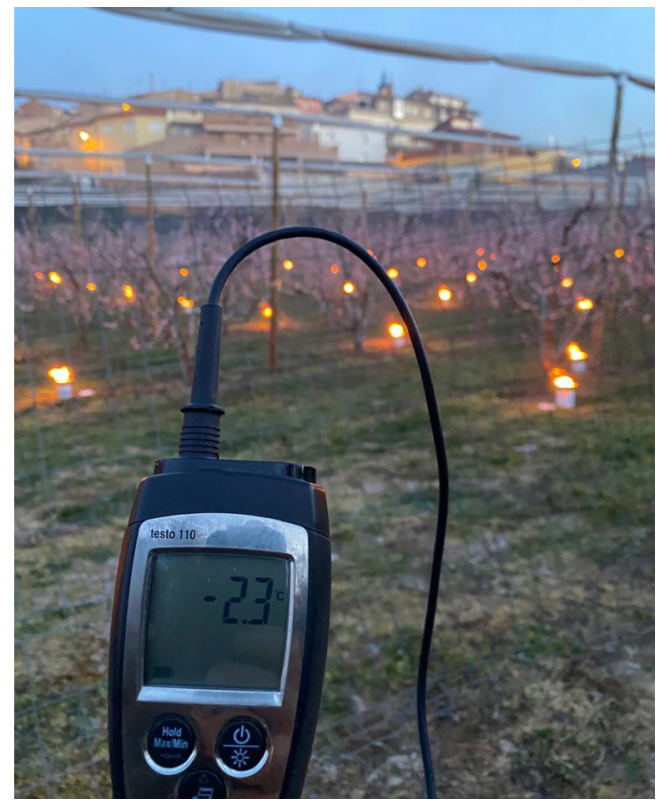

Figura 2. Lucha antiheladas con quemadores de parafina, Valle del Manubles, Comunidad de Calatayud, Zaragoza, en marzo 2021.

Foto: Eustaquio Acón. 
Hasta mayo en general no se puede dejar de sufrir por este asunto, y es que como dicen por el Valle de Benasque: "Mayo arribau, hivert acabau".

Mayo es el pórtico del verano, y sobre todo estos últimos años, aún así "mayo debería ser arreglado, ni frío ni acalorado, ni muy seco ni muy mojado".

"Arreglado" bien podría resumir la sensación térmica de confort que podemos encontrar en muchos puntos de nuestra comunidad, incluso en el Valle del Ebro si el cierzo lo permite, y que anima a exclamar: "en hora buena vengas mayo, el mejor mes del año".

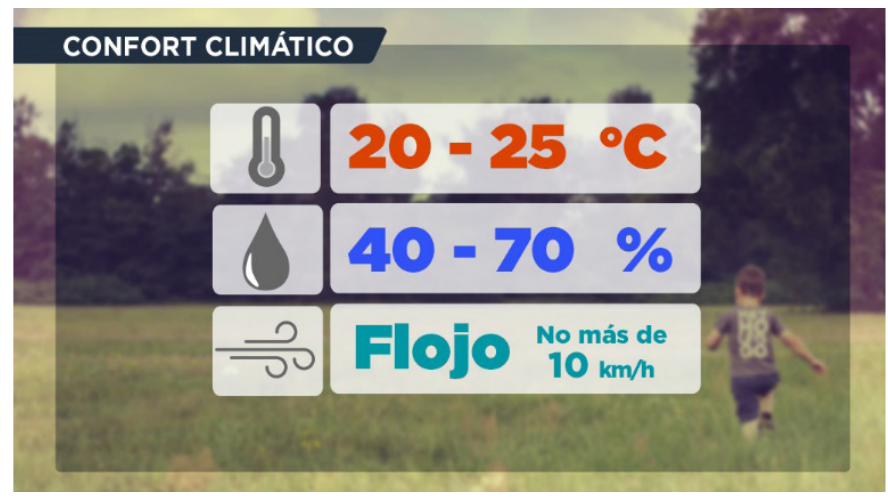

Figura 3. Parámetros climáticos de confort climático. Archivo Aragón Tv.

Fuente: Elaboración propia.

Esta sensación suele darse en las horas centrales de algunos días de mayo y también de finales de septiembre o incluso se alarga a principios de octubre en el Valle del Ebro, cuando realmente la ropa de entretiempo finalmente sale del armario para cumplir su papel durante toda una jornada, algo poco habitual en nuestros lares por ese paso brusco del invierno al verano y viceversa que más adelante trataremos.

Eso si el viento lo permite, un viento que en primavera según el refranero cambia de dirección continuamente, añadiendo pues otro elemento que es un reflejo de la variabilidad meteorológica primaveral, especialmente en el mes de marzo: "Marzo ventoso", "en marzo la veleta, ni dos horas quieta". Efectivamente el paso de sucesivos sistemas frontales y la disposición de los centros de acción cambiantes en poco espacio de tiempo implican que el viento varíe de forma frecuente su presencia, su dirección, y su intensidad, aun así, en Aragón la dinámica atmosférica manda, y la orografía también, y el viento es una constante en nuestro clima, registrándose pocos días de viento en calma durante el año en cualquier estación. 


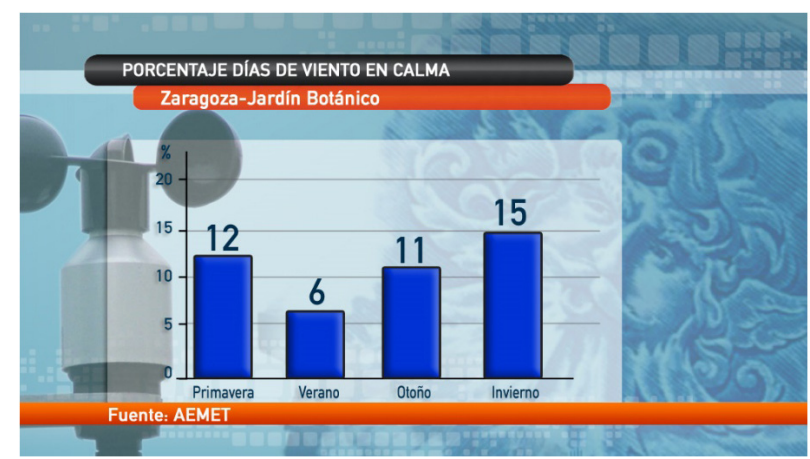

Figura 4. Archivo Aragón Tv.

Fuente: Elaboración propia.

La componente predominante en nuestra comunidad seguirá siendo la del $4^{\underline{0}}$ cuadrante, y en especial el omnipresente cierzo que soplando entre WNW y NW se lleva la palma, particularmente en el valle del Ebro, con una presencia notable a lo largo del año frente a cualquier otra dirección.

No podemos determinar con los datos que tenemos que en marzo o en primavera se mueva más el viento, ni que haya un patrón distinto en cuanto a una mayor variabilidad de la dirección del viento que en otras estaciones, tan solo señalar una ligera mayor presencia en primavera (y también en verano) de los vientos del $2^{\circ}$ cuadrante, el bochorno, "siendo muy notable su valor climatológico por coincidir generalmente con periodos de lluvias" (Biel, 1952).

Quizás a marzo se le denomina "ventoso" porque no haya otro meteoro más destacable en el tercer mes del año, una vez pasado el crudo invierno y a la espera de las precipitaciones del "abril lluvioso". Y es que si algo caracteriza también la primavera es por ser la estación más lluviosa del año en numerosas comarcas aragonesas.

El archiconocido y recurrente "abril aguas mil" así lo certifica, aunque muchas veces esas lluvias"caben en un barrit" lo que puede indicar que en abril llueve muchos días, pero muchos de ellos en forma de chaparrón de corta duración que aportan menos de lo que pudiéramos pensar al cómputo final del mes aunque la sensación sea otra.

Abril es un mes lluvioso en nuestra comunidad, aunque mayo lo supere en muchas zonas, y algún mes otoñal también, además de la importante precipitación invernal de áreas del Pirineo.

En cualquier caso, la mayor parte de las comarcas aragonesas siguen la pauta en cuanto a precipitaciones de los climas mediterráneos con un ritmo equinoccial, primavera y otoño. 


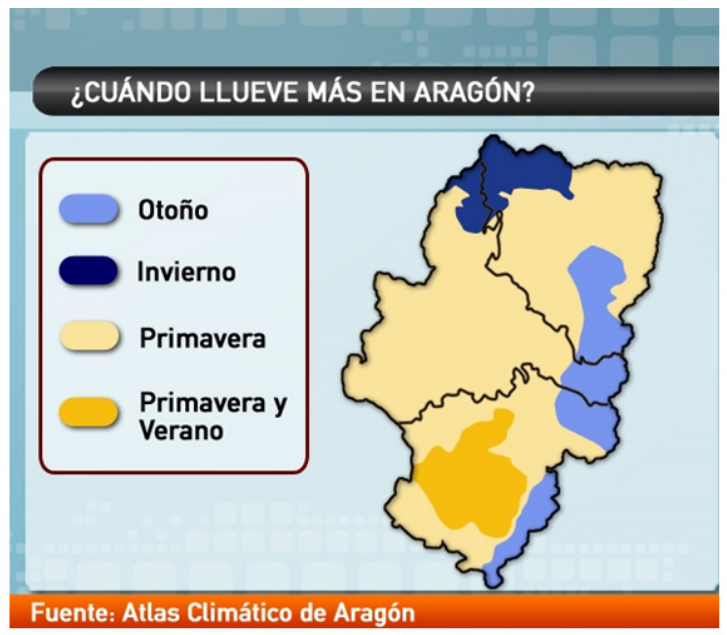

Figura 5. Estacionalidad de las precipitaciones en Aragón. Archivo Aragón Tv.

Fuente: Elaboración propia.

Nuestra comunidad, con una importante producción cerealista, 63\% de la superficie cultivada de Aragón, (IAEST, 2020), se ve beneficiada por las precipitaciones primaverales tras el parón invernal de precipitaciones, agua que permita que la espiga vaya cuajando, creciendo y "granando" ya en mayo. Y a pesar de que el regadío ocupa un porcentaje importante de esos cultivos "agua de riego no quita agua del cielo".

A las precipitaciones frontales se les unen ya los chubascos de carácter tormentoso especialmente en los sistemas montañosos y particularmente en la provincia de Teruel, con el paso de aire frío en altura a través de vaguadas o pequeñas bolsas de aire frío, sobre todo en mayo.

En gran parte de la mitad occidental de la comunidad mayo suele ser el mes más lluvioso del año, algo que le viene muy bien al campo y al monte, porque además las temperaturas suben rápidamente: "lo que mayo riega, mayo lo seca".

En cualquier caso, entre abril y mayo se dan las condiciones más oportunas para que la cosecha de cereal y otras, sean un éxito: "abril y mayo tienen la llave del año", "a tú que te pleba tot el año, a mi entre abril y mayo", "abril banyat, de pa va carregat" este último ya dirigiendo sus deseos a la cosecha del cereal.

Eso sí, nunca llueve a gusto de todos, y seguramente quien cultiva la cereza no está tan de acuerdo en estos refranes, muchas de las cerezas se "aguachinan" con la lluvia de finales de abril o mayo, pero es evidente la importancia secular del cultivo del trigo y la cebada para la supervivencia antaño frente a lo reducido, y no por ello menos im- 
portante, del cultivo de la cereza y otras delicadas frutas. No hemos encontrado refranes en este sentido.

En cualquier caso, que llueva, pero que haga sol.

"Marzo, marzero que faiga buen sol dimpués d'un auguazero", o "en may cada día un raig" como dicen por el Matarraña (en mayo cada día un rato).

Ambos describen cómo son las precipitaciones en forma de chubasco, la gran mayoría de veces, y seguramente la conveniencia de que el sol facilite otros procesos en la planta que lleven la cosecha a buen puerto (maduración, polinización, etc.)

Agua y sol, y a veces simultáneamente, "tiempo del caracol" pero también uno de los momentos estelares junto al verano de la presencia del arco iris "con agua y sol, el arco del Señor" que trataremos más adelante.

$\mathrm{Y}$ avanzando en el calendario primaveral "llegando al 40 de mayo el verano ya ha comenzado".

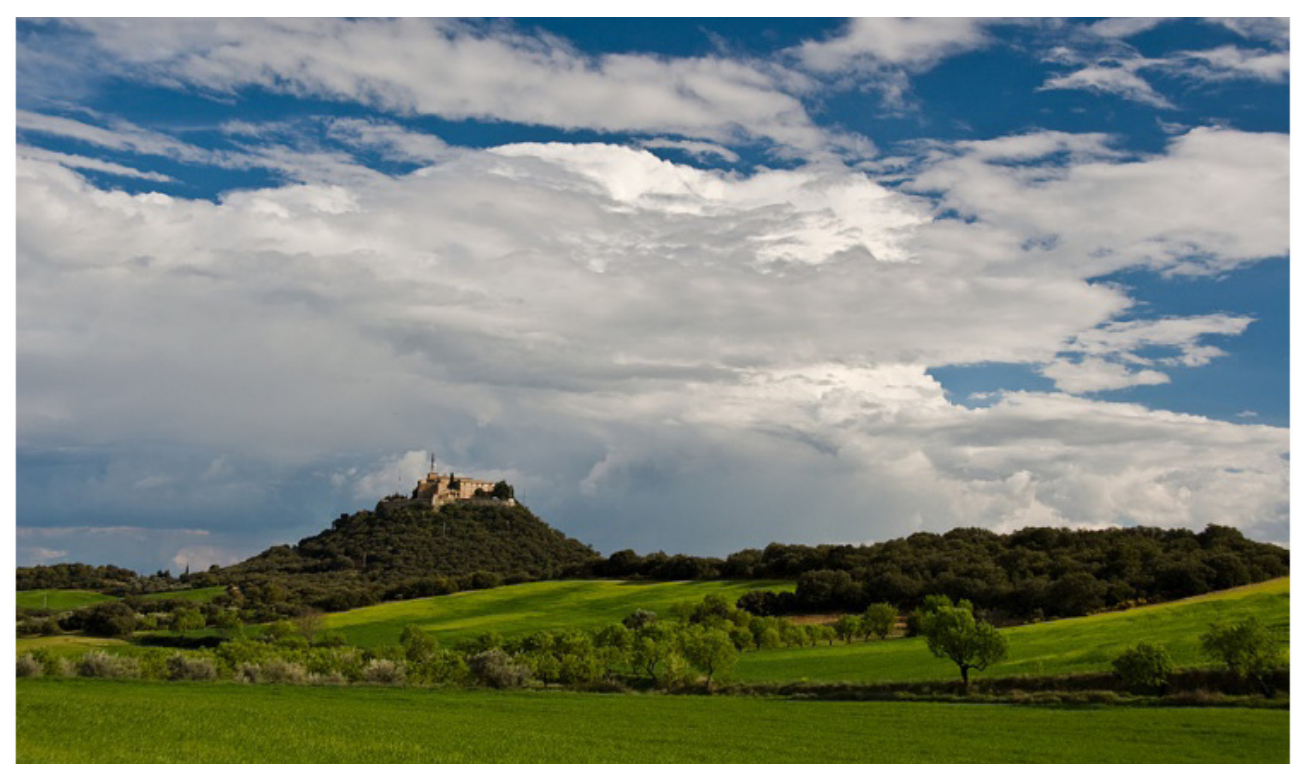

Figura 6. Estado del cereal en el mes de abril en el Somontano de Barbastro (Huesca). Foto: Miguel Marqueta. 


\subsection{El verano}

La estación estival oficialmente comienza el día del solsticio de verano, es decir cuando los rayos del sol caen perpendicularmente en el Trópico de Cáncer, el punto más cercano a nuestras latitudes de todo el año. Sin embargo, la tradición popular en nuestro país y en muchos otros del resto de Europa marca el inicio del verano, la noche de San Juan: "Al fin y al cabo por San Juan ya es verano".

Es el momento en el que los rayos del Sol caen de forma más directa y duradera sobre nuestras latitudes, el momento de mayor energía recibida, por lo tanto, más calor que conlleva un aumento considerable de temperaturas: "Julio, beber y sudary en vano el fresco buscar", y por supuesto más horas de luz solar, aunque a partir de este momento, poco a poco, el día irá perdiendo segundos frente a la noche. Las bondades de la luz solar, "donde entra el sol no entra el doctor, se ensalzan más en esta época con más de 15 horas de luz solar al principio de la estación: "Junio es todo día, jóvenes y mayores tienen más vida".

Es difícil sobrellevar los días caniculares en las horas centrales del día incluso a la sombra especialmente julio y también agosto "que frie el rostro" y sobre todo la segunda quincena del mes de julio y primera de agosto: "De Virgen a Virgen los sesos se derriten" (Santa Ana, 26 de julio y la Virgen de Agosto, día 15).

Evidentemente todos estos refranes tienen validez exclusivamente en el hemisferio norte, en el sur comienza un invierno de 3 meses.

"Iulio y agosto cada uno como el otro" aunque agosto ya tiene una menor insolación y eso se refleja en las temperaturas nocturnas, con mínimas algo más bajas, no durante el día, y sobre todo a finales de mes: "Agosto frío en rostro, a ultimos que no a primeros".

Algo que se nota especialmente en las largas noches y madrugadas vividas en nuestros pueblos que celebran sus fiestas patronales con verbenas hasta la madrugada que obligan a vestir ya algo de abrigo, aunque las temperaturas mínimas medias de julio y agosto sean similares.

El estío actualmente es la estación festiva por excelencia, sobre todo agosto, y bien por el parón en las tareas agrícolas o bien por el calor reinante, existe la posibilidad de descansar algo más y de ocupar el ocio, como no, pensando ya en cómo será la próxima temporada en función de lo que regale el cielo.

"Agosto guarda el secreto de doce meses completos" Es la época de "las cabañuelas", ese método de predicción tradicional basada en observar y anotar el tiempo que hace cada uno de los 12 primeros días de agosto y relacionarlos con el que hará en los 12 meses del año siguiente, algo que compartimos con muchas regiones no solo de Es- 
paña, sino también de Europa. En Aragón tenemos una particularidad a la hora de pronosticar el tiempo a tan largo plazo, concretamente en el Pirineo oscense: "Fer as calandras" con igual metodología pero eligiendo el periodo mágico de 12 días antes y después del día de Navidad.

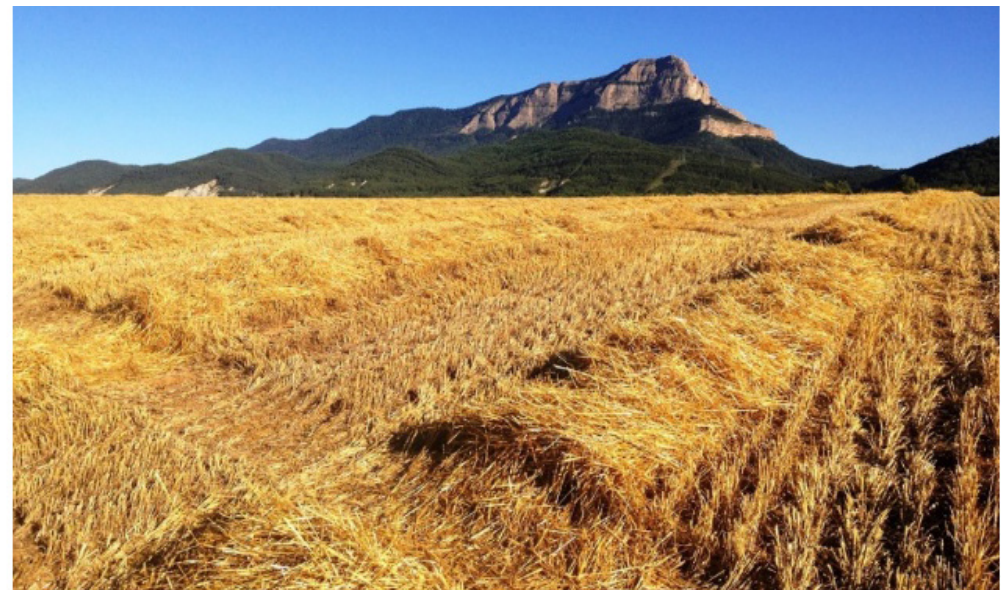

Figura 7. Cereal recién cosechado en julio, La Jacetania (Huesca).

Foto: Eduardo Lolumo.

La monotonía de los días estivales se ve reflejada en la poca variación del tiempo de un día a otro. Los tipos de tiempo en verano no son tan variados como los de las otras estaciones en la Península Ibérica y por extensión en nuestra comunidad, la omnipresencia del anticiclón de las Azores y la retirada al norte del frente polar suponen una época de estabilidad, aunque en Aragón se ve interrumpida por la frecuencia de tormentas estivales que pueden afectar a cualquier comarca.

En cualquier caso, "por mucho que quiera ser, en julio poco ha de llover".

Algo de agradecer la gente del campo que tiene que pasar muchas horas al aire libre recogiendo la cosecha, "dice junio al jornalero, ya dormirás en enero" "en junio la boz en el puño" o "al churiol, la forca al coll" como dicen en el Valle de Benasque, algo más tardana la cosecha aquí, en julio, debido a la altitud, mientras que en el Valle del Ebro ya se ha recogido todo.

El éxito de la cosecha depende por un lado de que el sol lo vaya madurando bien el grano: "Chuñ brillant, añ abundant", claro si mayo había dado todo lo que se esperaba de él y no se necesitase más lluvia, y en cualquier caso si llueve que no sea en forma de chubascos tormentosos con riesgo de granizo: "Las tormentas para San Juan, quitan vino y no dan ni aceite ni pan”. 
Aragón tierra de tormentas, sin duda. Es un paraíso para todo aquel que se precie de ser un "cazador de tormentas" especialmente la Sierra de Gúdar y el Maestrazgo en Teruel donde desde mayo hasta septiembre alguno o varios días a la semana es posible ver y oír este fenómeno atmosférico.

La elevada insolación supone un rápido caldeamiento del suelo, la rugosidad de nuestra orografía de considerable altitud en muchas comarcas origina unos contrastes térmicos acusados entre el suelo y las zonas altas generando gran inestabilidad si hay otras condiciones añadidas como el paso de vaguadas en altura, algo no inhabitual por las fechas. El calor y la convección a primeras horas de la tarde son el disparo de estas tormentas, luego el aire frío y por último el aporte de humedad en capas medias atmosféricas desde el Mediterráneo.

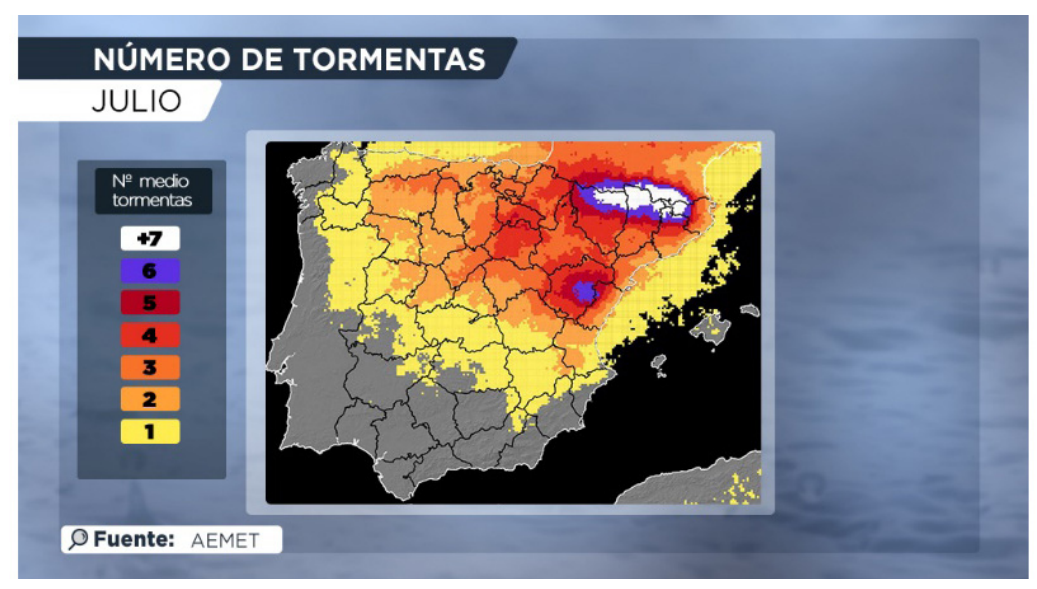

Figura 8. Mapa de frecuencia de tormentas en la Península Ibérica y Baleares. Archivo Aragón Tv.

Fuente: Elaboración propia.

Por eso muchos refranes aluden a las tormentas: "en verano lloverá, más primero tronará”. Es difícil encontrar precipitaciones frontales en esta época del año.

"Puerto escaldau, a las pocas horas regau" Las zonas de montaña actúan como trampolín del aire cálido acumulado a lo largo de un día elevándolo a la atmósfera donde puede encontrar aire frío y si hay otras condiciones de humedad e inestabilidad generarse una nube de desarrollo vertical de gran espesor y opacidad que irá creciendo y oscureciendo su base pudiendo alcanzar gran altitud llegando a un último estadio de desarrollo, el cumulonimbus, cuya cúspide quedara totalmente iluminada por los rayos del sol: "si sobre las negras las blancas ves, la tormenta segura es". 


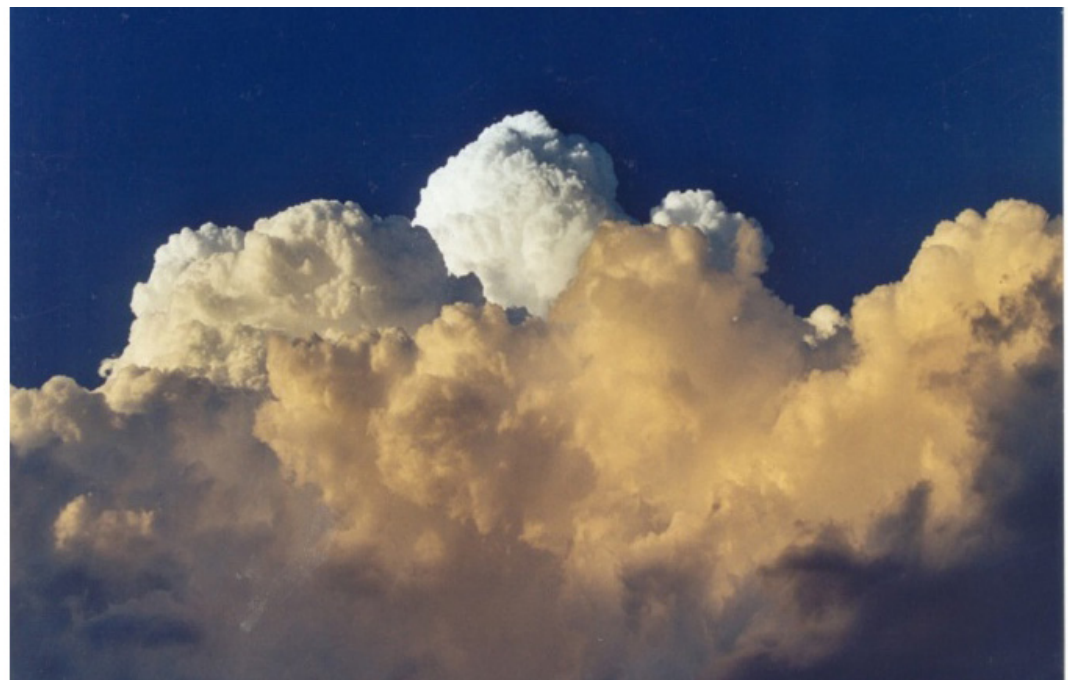

Figura 9. Fase avanzada en el desarrollo de una tormenta. Cumulus congestus, Zaragoza.

Foto: Eduardo Lolumo.

Nubes de tormenta que por el Jiloca y el Campo de Daroca y las vecinas comarcas de Guadalajara bautizan con nombre propio: el cura Corbatón: "Cuando sale el cura Corbatón, habrá tronada antes de días dos".

El caldeamiento del suelo y de la capa de aire más próxima a lo largo del día es el disparo de salida, aunque no siempre dé como resultado una tormenta: "Cuando el sol mucho calienta, barrunta tormenta", "tronada por la mañana, no quita jornada", los procesos convectivos en una situación de relativa inestabilidad se dan a partir de media mañana y sobre todo por la tarde cuando se ha acumulado más calor: "Cuando por la mañana sientas tronar, no te alejes del lugar".

La presencia de chubascos tormentosos en el verano es de tal importancia que algunas comarcas turolenses tienen el máximo de precipitación en este trimestre.

Agua de poca eficacia en los cultivos, y ni siquiera en el monte, donde además, puede provocar incendios especialmente con tormentas secas y rayos durmientes.

"El agricultor quiere agua de temporal y no agua de tronada..." y menos con pedregada, añadiríamos.

Y de nuevo hay que mirar al monte para poder determinar el tiempo venidero, en este caso el tormentoso donde antes crecerán las primeras nubes de evolución. Numerosas comarcas apuntan a picos cercanos: 


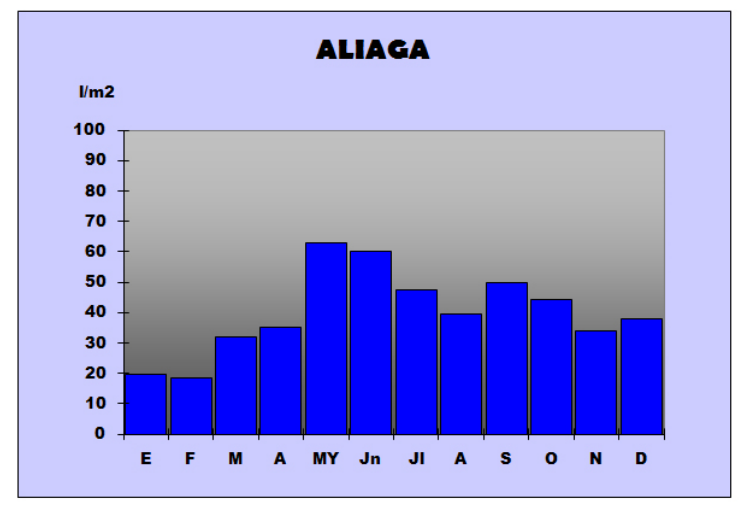

Figura 10. Distribución anual precipitaciones Aliaga (Teruel).

Fuente: Atlas climático de Aragón. Elaboración propia.

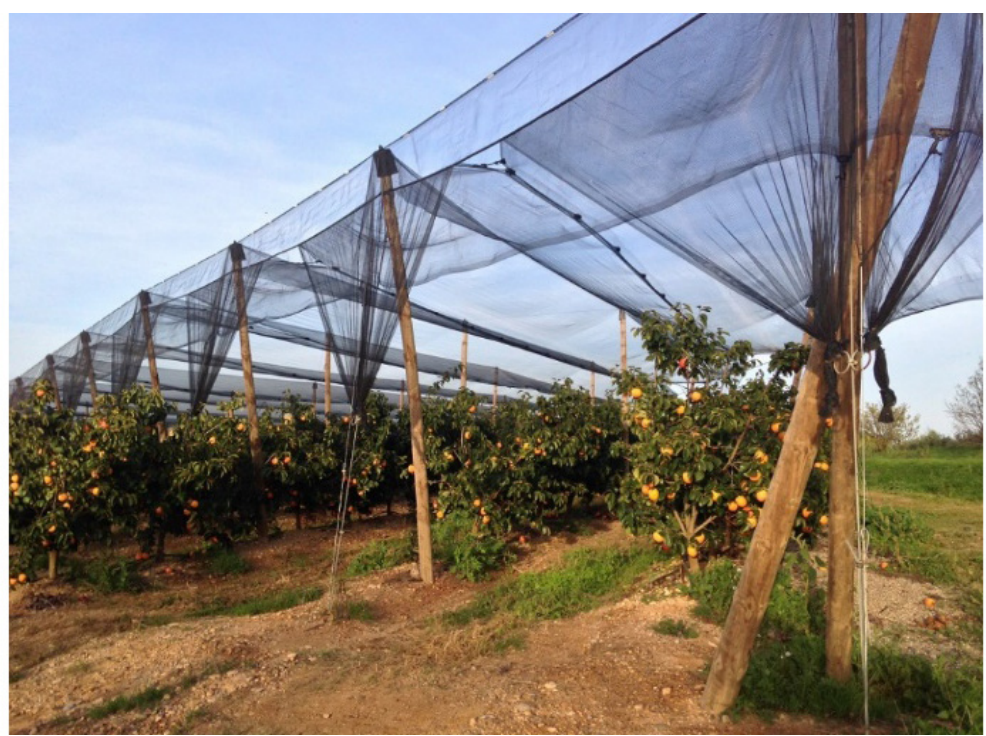

Figura 11. Métodos directos de lucha antigranizo con mallas en un cultivo de kakis, Zaidín (Huesca).

Foto: José Ibarz.

- Bal de Chistau, Sobrarbe: "Truenos por Voltorín (pico cercano), agua de camín".

- Maestrazgo: "Relampaguea por las Parras (de Castellote) el agua hasta las garras".

- Matarraña: "Rellampecs al Port, aigua al foc". 
Y unidas a las tormentas y a los cambios bruscos en el cielo que generan, será muy posible ver el gran espectáculo de la naturaleza que consiste en la descomposición de la luz solar en los siete colores que la componen a través de las gotitas de agua que caen de la nube, el arco iris, denominación comúnmente usada en toda España aunque con muchas variantes que en Aragón se denominan como "arco de San Juan" o "arco o barra de San Chuá", en gran parte del Pirineo, "cinta de San Juan" en Aragüés del Puerto (García Moutón, 1984) o "ratlla de San Martín" en el Matarraña y Bajo Cinca.

Magnífico efecto óptico de corta duración que tiene mucho de mágico y al que se le puede adjudicar una significación meteorológica y predictiva muy concreta allí donde se ve y cuándo se ve:

"[...] suele decirse que "cuando aparece el arco iris por la tarde es señal de buen tiempo posterior". Cosa lógica, que nada tiene que ver, dicho sea de paso, con el arco iris, sino con el hecho de alejarse la posible perturbación hacia el Este (por la tarde, el Sol está por el Oeste y de allí viene el arco iris). En nuestras latitudes, en las que las lluvias se desplazan habitualmente de Oeste a Este, este alejamiento de perturbaciones indica, claro, una posterior mejoría del tiempo.

[...] Cuando hay arco iris matinal, lloverá pronto y durante todo el día. Nos parece muy justo, si estudiamos el caso como antagonista del anteriormente visto respecto al arco iris vespertino. Por la mañana, el Sol está al Este, y el arco iris aparece al Oeste, por donde vienen las nubes y las lluvias. Lo cual suele significar que en su habitual trayectoria de Oeste a Este, dichas nubes y lluvias no tardarán en llegar a nosotros, y con ellas la perturbación que las acompaña».

(Manuel Toharia, 1985, 98-99 p.)

Y así lo certifica el refranero, bien para una predicción a corto plazo, muy certera: "Ratlla de Sant Martí al matí,/l'aigua és aquí; ratlla de Sant Martí a la vesprada,/l'aigua és pasada".

O bien otra a más largo plazo que ofrece más dudas: "Arco iris al atardecer, buen tiempo al amanecer" o "el arco San Chuan, aigua pa deman" como dicen por las Vilas del Turbón, en La Ribagorza.

Por último, apuntar que hay pocos refranes en esta estación que hagan referencia a aspectos fenológicos ya que no hay movimientos migratorios destacables, tan solo la conclusión de algunos con la cría de las cigüeñas en este caso: "Para San Juan, los cigoñinos a volar".

El fin del verano se manifiesta ya en septiembre, el fin de un ciclo con abundancia de productos cosechados y recogidos que permiten un alivio en las faenas, y además con unas temperaturas más llevaderas disfrutando todavía de muchas horas de luz solar. "Septiembre, frutero, alegre y festero" pero esto ya será otra estación climáticamente hablando. 


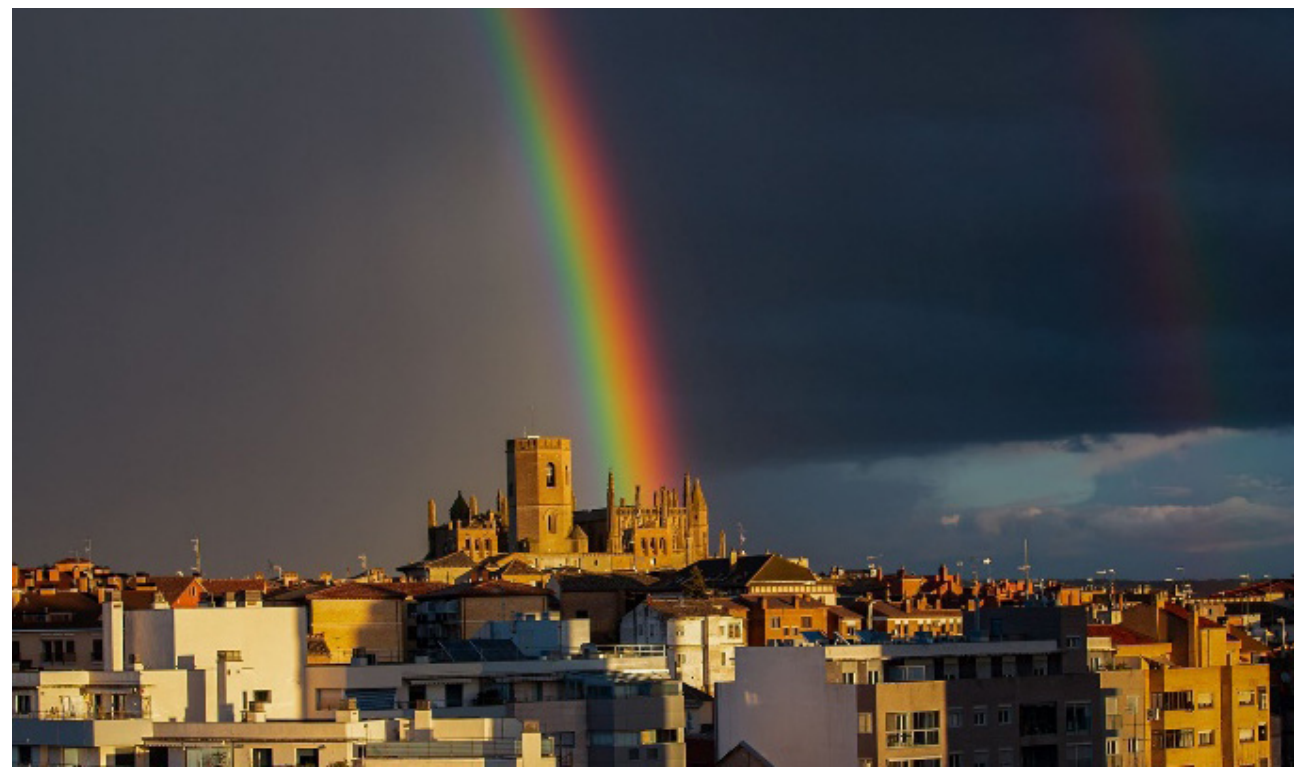

Figura 12. Arco iris en Huesca.

Foto: Luis Miguel Guerrero.

\subsection{El otoño}

Cambio de estación, y haga el tiempo que haga o debería hacer, lo que es evidente es que los días se van acortando, algo que ya en agosto se percibe por las noches, pero que en septiembre es más palpable por el día y por la noche, el día se acorta rápidamente frente a la noche en esta época del año (Anuario Astronómico) entorno al equinoccio de otoño, otro momento astronómico en el que los rayos vuelven a caer perpendicularmente en el Ecuador como ya hizo en primavera. La duración del día y la noche se van igualando: "Por San Mateo (21 de septiembre) tanto te veo como no te veo".

De igual manera que apuntábamos con la primavera estamos hablando de una estación de transición, pero con unas características que todos reconocemos como "tiempo de otoño" aunque en los últimos años cada vez sean menos abundantes.

De nuevo, como ocurre en la primavera, el hecho de ser una estación de transición ya le confiere parte de su personalidad. Se alternan tipos de tiempo muy diferentes en cortos espacios de tiempo. En esta época son muy reconocidos tanto los "veranillos" (San Miguel, San Martín, rosas otoñales...) como los primeros fríos y lluvias de temporal de borrascas atlánticas, cada vez más frecuentes aquellos y menos estos. 
Variable, inestable, cambiante, comienza el otoño: "Septiembre o se lleva los puentes o seca los puentes", "el tiempo de octubre loco, derrama de todo un poco".

La irregularidad propia en cuanto a precipitaciones del clima mediterráneo, al que la mayor parte de nuestra comunidad pertenece, se percibe más en esas estaciones llamadas de transición, y septiembre o incluso octubre pueden adoptar un matiz más veraniego o más otoñal.

Pero en cualquier caso en otoño, y no en primavera, se da una circunstancia en la Península Ibérica y Baleares que caracterizan muy bien el principio de la estación y que mucho tiene que ver con el calor acumulado durante el verano, especialmente en el cercano mar Mediterráneo que, junto a otros factores atmosféricos (DANA) y geográficos, puede generar situaciones de gran inestabilidad que ocasionen chaparrones tormentosos de especial virulencia en las comarcas ribereñas del Mediterráneo y que pueden afectar a las comarcas más orientales de nuestra comunidad especialmente de la provincia de Teruel "con episodios extremos de precipitación en la comarca del Matarraña, octubre 2000" (Lolumo, Berlanga y Fernández, 2014): "Dejan recuerdos espantosos los octubres que comienzan tormentosos".

En cualquier caso otoño es una estación que todos evocamos como lluviosa tanto por la situación antes descrita como por lluvias de temporal que puedan venir por el Atlántico además acompañadas de un notorio descenso en los termómetros: "El cordonazo de San Francisco (4 octubre) por tierra y mar se ha de notar" aunque en los últimos años pocos "cordonazos" recibimos con una menor presencia de tipos de tiempo del Noroeste ligados al chorro polar con sus frentes activos o incluso el paso de borrascas sobre nuestro país, en favor de una mayor expansión de la atmósfera subtropical con "estructuras y circulaciones que confirman la tendencia creciente hacia la subtropicalización de nuestro entorno geográfico" (Rivera, 2020) Para esta nueva situación, evidentemente, el refranero que tratamos no tiene ninguna aportación.

A pesar de lo dicho, y hasta ahora al menos, las precipitaciones vendrán del Oeste o del Noroeste, ya que "las borrascas atlánticas genuinas suponen las tres cuartas partes del total de las que afectan a la Península Ibérica" (De Terán, 1978 p. 152).

Desde Mariano Medina pasando por José A. Maldonado y llegando a nuestra Silvia Laplana hemos escuchado en el parte meteorológico de TVE que "un frente entra por Galicia", nunca por Murcia...evidentemente responde a la dinámica atmosférica de nuestras latitudes y al predominio de vientos del componente oeste. Por lo tanto los refranes de nuestra tierra nos obligan, por al momento, a dirigir nuestra mirada al oeste para intentar saber qué va a pasar en las horas inmediatas. Ahora el Meteosat y el radar ayudan, pero nunca va mal otear el horizonte. 


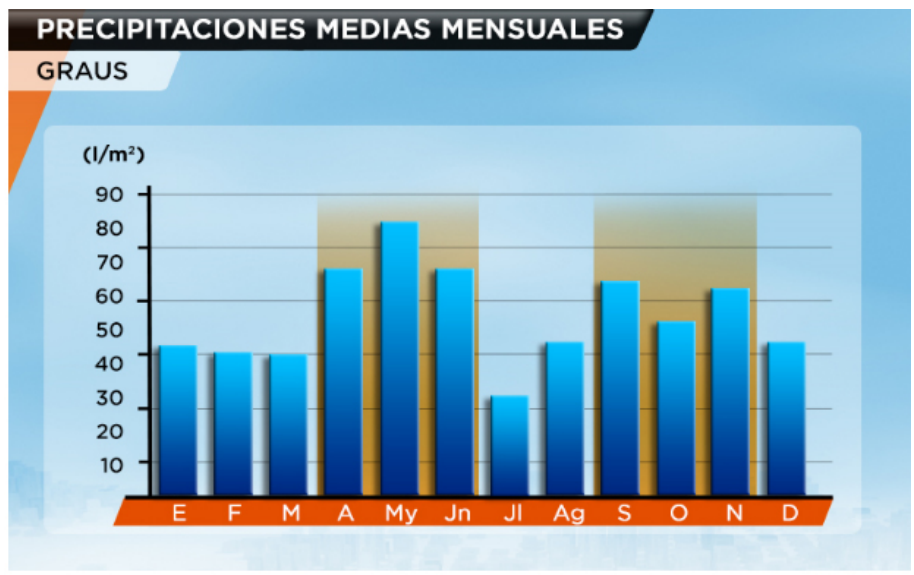

Figura 13. Distribución precipitación mensual. Graus (Huesca).

Fuente: Atlas Climático de Aragón. Elaboración propia.

"Si llueve en Madrid a las tres horas aqui" aseguran por Calatayud, refrán que no solo apunta por dónde viene el frente, sino la velocidad del mismo que está dentro de la media de avance que suelen tener $(40 \mathrm{~km} / \mathrm{h})$.

Y de nuevo las montañas nos van a dar también respuestas o al menos indicios de lo que va a pasar, mirando efectivamente al oeste y buscando montes, picos y cerros cuya singularidad y presencia sea relevante en la zona.

\section{"Gratal con gorro agua hasta el morro, y con montera, agua hasta la ribera".}

Bien presentes tienen esta mole caliza los oscenses e incluso los zaragozanos de los Llanos de la Violada, hay otros en esas primeras estribaciones del Prepirineo oscense, pero ninguno se asoma con mayor gallardía a la Hoya de Huesca.

Otro monte emblemático y al que mirar por muchas razones es el Moncayo, en el confín occidental de la provincia de Zaragoza de elevada altitud y majestuosa presencia: "Si en Moncayo hay ventana, no lloverá mañana", (si se ve con claridad el monte), "cillo en Moncayo, pronto verás lleno o vallo" (cillo, cubierto de nubes).

Lo mismo ocurre en La Ribagorza con otro monte emblemático: "Cuando hi ha boira en Turbón, hi agua en tot Aragón”.

De todas formas, en Aragón, y en especial en el Valle del Ebro, son bien recibidas las precipitaciones que provienen de situaciones del Este y SE que a pesar de ser poco habituales, son mucho más efectivas y pueden dar lugar a varias horas de lluvia continua y pausada en forma de temporal. 


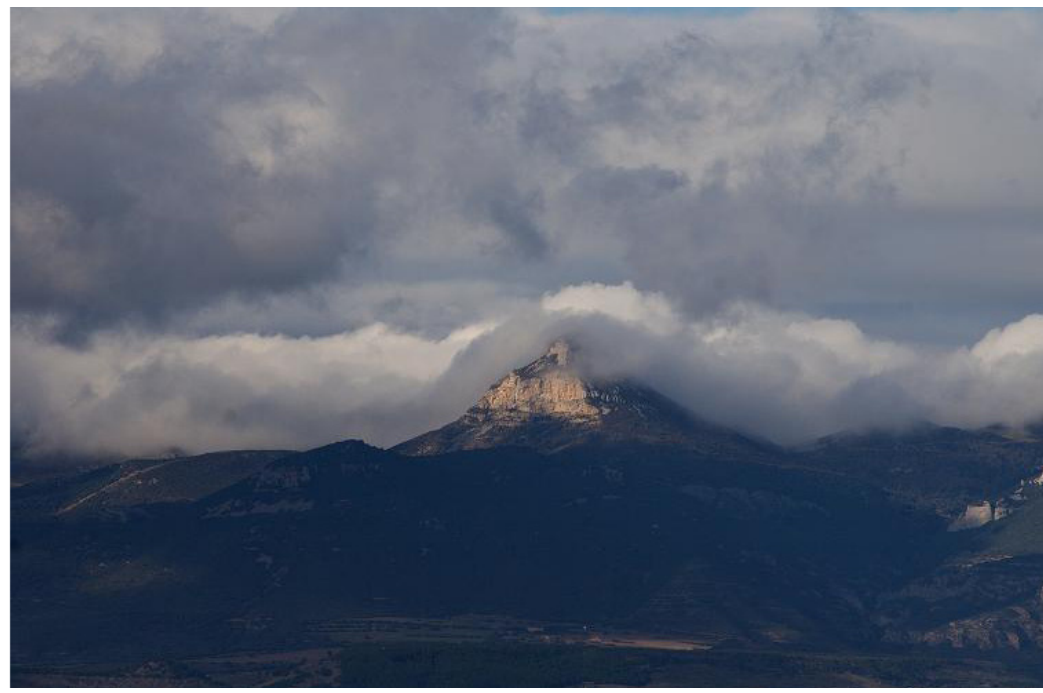

Figura 14. Pico Gratal, Hoya de Huesca, con "montera" (estratos) en su cumbre.

Foto: Eduardo Lolumo.

"Aire de Pina (de Ebro) Ilena la badina" dicen por Huesca y el Bajo Gállego, "bochorno frío aumenta el río", "aire de Llevant, aigua davant (Bajo Cinca).

Y hablando de precipitaciones y nubes, mirar al cielo directamente puede ayudar más que ninguna otra cosa en un pronóstico próximo y certero. Hablaríamos del lenguaje de las nubes que el refranero tiene muy en cuenta.

A veces encontramos nubes finas, las primeras que suelen conformar un frente nuboso, los cirroestratos, y según se dispongan las nubes y los rayos del sol que inciden en los cristales de hielos que las configuran, nos dan un efecto óptico, el halo solar o el "rolde de sol' como se dice en muchos puntos de Aragón, y que puede indicar lluvia próxima:

"El rolde de Sol moja al pastor, el de la Luna, lo enjuga".

Tras estas nubes altas seguramente vendrán otras medias, los altocúmulos, algo más compactas pero sin capacidad efectiva para dejar precipitaciones, anticipando a otras que quizás puedan hacerlo:

"Cielo a borreguicos, agua a cantaricos" "cel a petxinetes, aigua a les bassetes"y que no son patrimonio exclusivo de la paremia española: "A mackerel sky, not a 24 bours dry".

A veces hay que mirar al suelo para tener más indicios. Ocurre con la lluvia y cómo se comporta al llegar al suelo. 


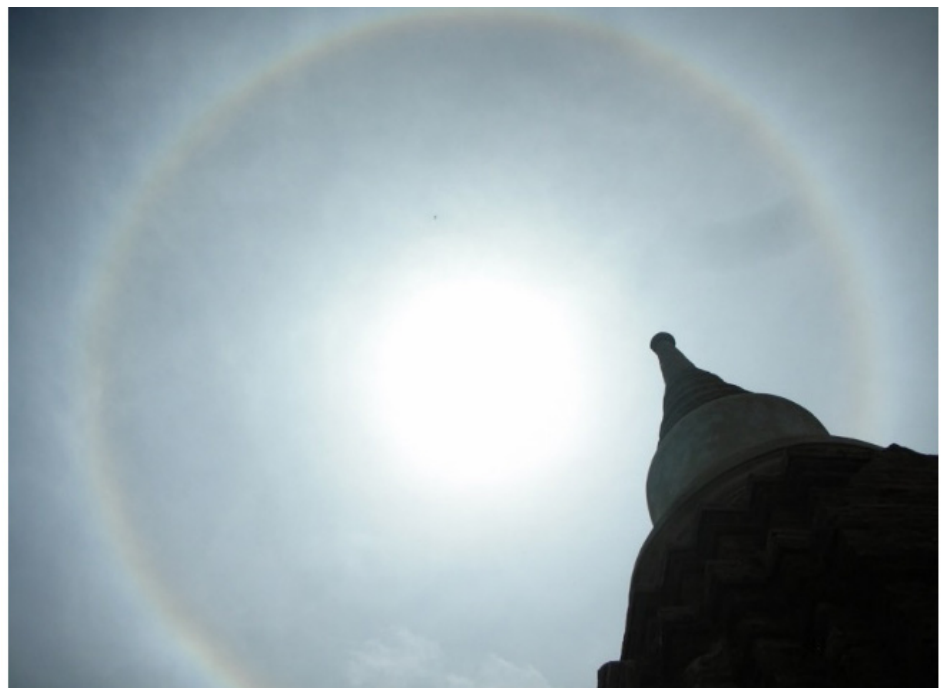

Figura 15. Halo solar y cirroestratos en Tailandia.

Foto: Felipe Biezma.

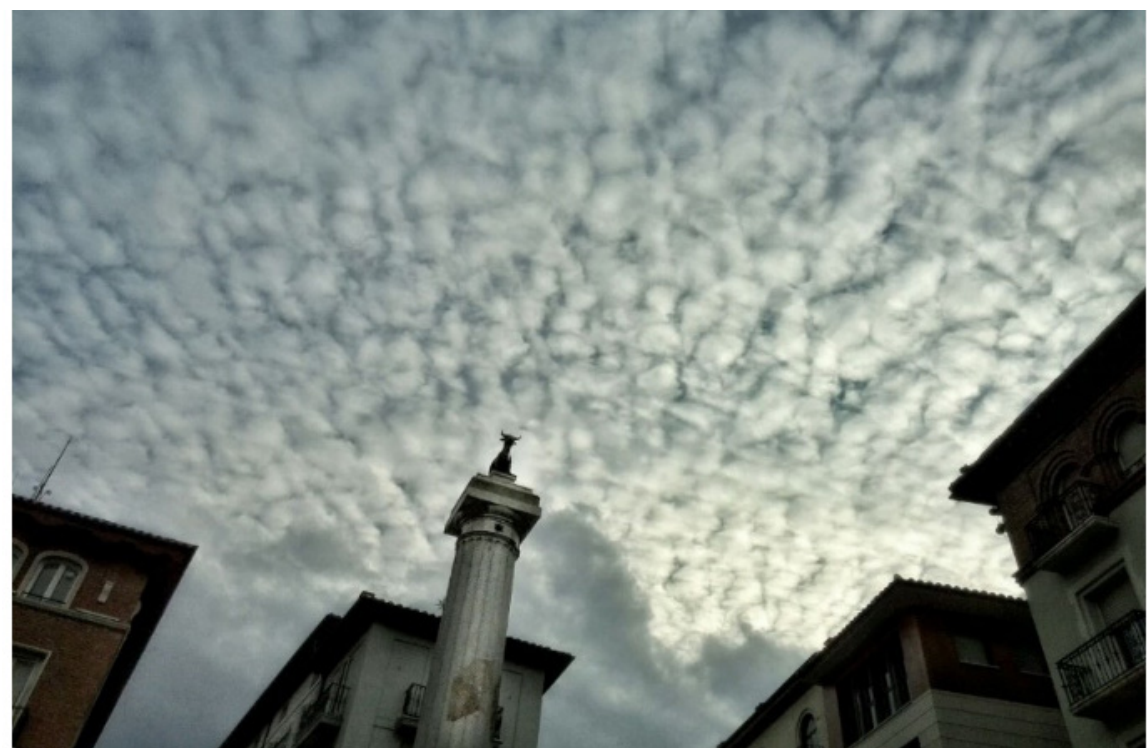

Figura 16. Altocúmulos en Teruel.

Foto: Pedro Blesa. 
Seguramente hemos observado que a veces la lluvia forma burbujas, bombetas en los charcos que no duran mucho. Ese comportamiento de la lluvia recién caída en el charco indica que puede seguir lloviendo un rato más debido a una ley química con nombre propio, la ley de Le Chatelier y que en aragonés se resume así: "Si fa a'mbolletas, ya puedes abrir as basetas” (¿se le puede pedir más a la cultura popular?).

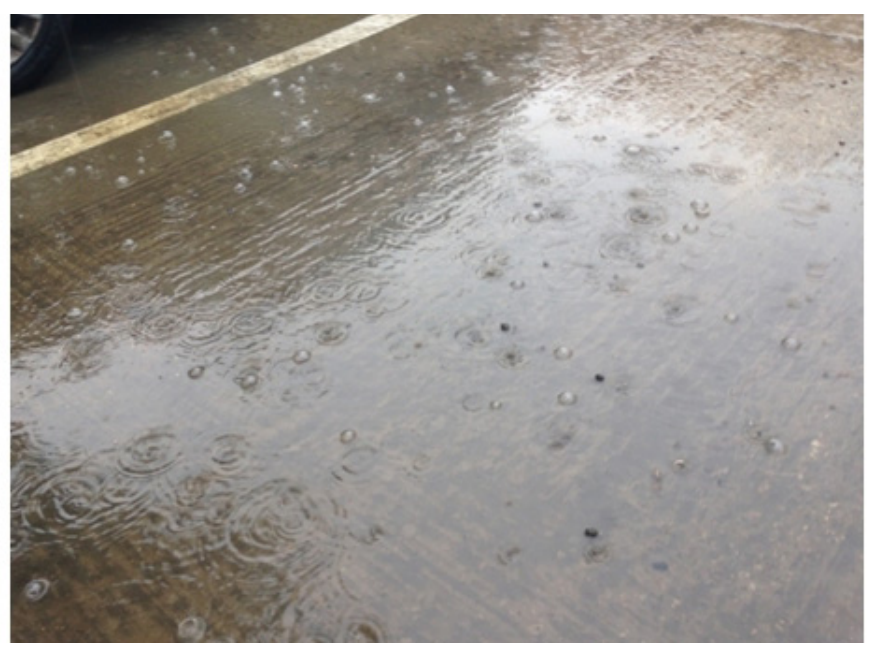

Figura 17. Lluvia formando burbujas al caer, Zaragoza.

Foto: Eduardo Lolumo.

Tras la sequía estival las lluvias del otoño ponen en marcha un nuevo ciclo hídrico, es el inicio del año agrometeorológico, y del hidrológico, pensando ya en una nueva siembra del cereal: "En seco o en mojado por San Lucas (18 octubre) ten sembrado" para los más tempraneros, algunos más tardanos "para noviembre quien no sembró, que no siembre" y si nos apuran hasta fin de mes, "ta San Andrés, no siembre mes".

Y el calendario seguirá recordando en otoño otras tareas que toca realizar, la trashumancia por ejemplo, el ganado baja de los pastos de verano del Pirineo y vuelven a un régimen de estabulación o cercanía a la finca: "De mayo a San Miguel pastor quiero ser, de San Miguel a mayo que las cuide el amo".

La vendimia que comenzó en septiembre o en agosto ya en muchas zonas, sigue su curso: "Septiembre el vendimiador, corta racimos de dos en dos", y a la que tomará relevo más adelante la cosecha de la oliva: "Por Santa Catalina (25 de noviembre) todo el aceite tiene la oliva", sin olvidar el azafrán por tierras del Jiloca: "Si en noviembre las flores dan, coge el azafrán". 
Sea como sea comienza una nueva etapa en cuanto al monte y al campo se refiere: "En octubre caída de hojas y lumbre" y la naturaleza ya da muestras de movimiento tras el parón estival y el próximo inviernal: "Cuando oigas las grullas pasar, señal de que el tiempo va a cambiar" aves que adornan con su formación regular y característico trompeteo el cielo otoñal en nuestra comunidad atravesándola de norte a sur aunque ya varios miles permanecen en nuestra comunidad especialmente en la Laguna de Gallocanta, con un calendario claro: "Para el Pilar vienen y para San José se van" aunque se va observando que la fecha de vuelta a sus cuarteles de verano en Centro Europa se suele adelantar como ha ocurrido este año y en anteriores.

Y ya que hablamos del Pilar, la fiesta más reconocida en el calendario festivo en nuestra comunidad, apuntar que hay un buen puñado de refranes que definen la temperie de ese periodo festivo, uno de ellos dedicado al cierzo que sin duda estará presente algún día u otro de las fiestas y que con cierta socarronería dice el refrán: "Ziercera en o Pilar ni bueno ni raro, ni bien, ni mal...".

El otoño, como la primavera, con acusados cambios de tiempo, acusa la presencia del viento como quizás ninguna otra estación, al menos en gran parte de nuestro país: "En otoño la mano al moño" aunque ya hemos comentado que, en Aragón, lo de aguantar el mano al moño podría llevarse en cualquier estación, sin distinción.

Y ligada a las precipitaciones y al descenso de temperaturas, no podemos dejar de hablar de la nieve en nuestras sierras: "Ta Todos Santos, la nieu pe's cantos" (montes altos) dicen por la Bal de Chistau

"Ta San Andrés a nieu por os piez," "por San Andrés nevadicas tres" claro en la montaña, porque ni en el Valle del Ebro ni en los Somontanos se la espera.

De todas formas la nieve irá apareciendo cada vez más y en más zonas con un evidente descenso de temperaturas porque ya a partir de noviembre vamos camino del invierno: "De noviembre a Navidad, ya es invierno de verdad".

\subsection{El invierno}

"Días de diciembre, dias de amargura, apenas amanece y ya es de noche oscura".

Refrán que caracteriza muy bien la "oscuridad" de los días invernales en base a dos aspectos:

Por un lado, estamos ante el periodo del año con los días más cortos que culmina con el solsticio de invierno. El sol se eleva poco en el horizonte y dura muy pocas horas en nuestras latitudes, 9 horas frente a las 15 horas del verano. 
Por otro lado hay una mayor presencia de días muy nubosos o cubiertos bien por nubes o por nieblas.

A partir del solsticio el día irá creciendo en conjunto, pero lentamente: "para Reyes ¿no lo vedes?" "ta San Antón (17 enero) un paso de ratón" "para San Blas (3 octubre) una hora más", "ta San Maties (24 febrero) toque el sol per les sombries" (Benasque).

Es destacable ver como los refranes astronómicos son tan certeros como certera y exacta es la ciencia que tratan, la astronomía. Incluso algunos que pueden resultar contradictorios: "por Santa Luzía a más luenga nuei e o más curto día" no lo son. No es contradictorio el hecho de que el día del solsticio sea el más corto del año con que a partir de Santa Lucía (13 diciembre) el día ya no va acortando por el momento del atardecer, mientras que lo sigue haciendo todavía en el amanecer. Amanecer y atardecer no son simétricos a la hora de la velocidad de alargar o acortar el día.

Y un último matiz a destacar en el refrán de la "amargura decembrina" está relacionada con el estado de ánimo que puede generar en muchas personas el hecho de que no se vea el sol en el horizonte, en especial las personas meteorosensibles, que se consideran un 30\% de la población, agravando la percepción de algunas dolencias tanto físicas como psíquicas.

De todas formas aunque vayamos ganando minutos de luz solar, por lo tanto de energía incidente, la superficie terrestre y los mares vecinos acumulan la menor cantidad de energía del año para poder ser irradiada a la atmósfera, esto unido al acercamiento de masas de origen polar a nuestras latitudes hacen que enero sea el mes más frío del año: "Enero hiela el agua en el puchero", "en diciembre tiembla hasta el más valiente", "el día de San Vicente (21 enero), el frío te rompe los dientes" o incluso más tarde "ta la Candelera (2 febrero) la mayor nevera".

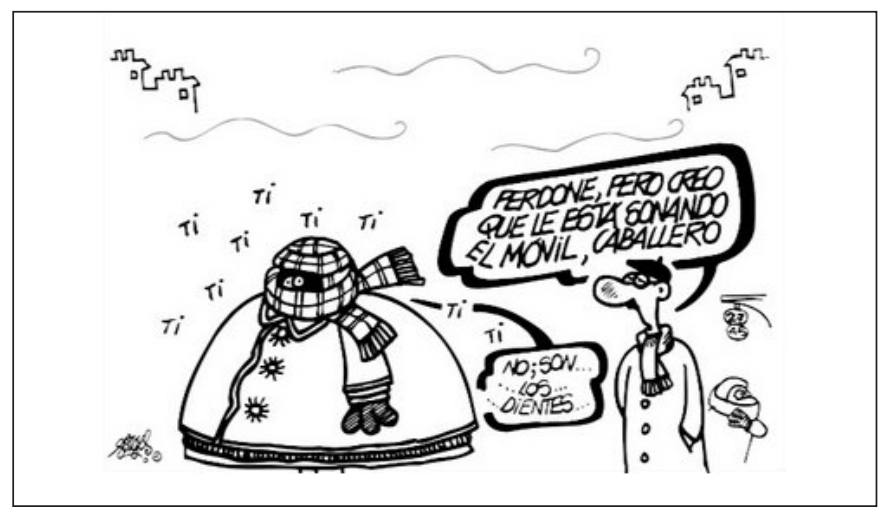

Figura 18. Viñeta meteorológica de Antonio Fraguas "Forges" IG: @soyfoges 
"Diciembre mojado y enero bien helado", "enero claro y heladero", así suele ser enero frío y con muchos días de cielo abierto si las boiras lo permiten, con una mayor presencia de tiempo anticiclónico. Es el momento de las grandes heladas nocturnas generadas en esas noches claras y estrelladas y encalmadas cuando la poca energía acumulada a lo largo del corto día no tiene ningún impedimento para "escaparse" al espacio.

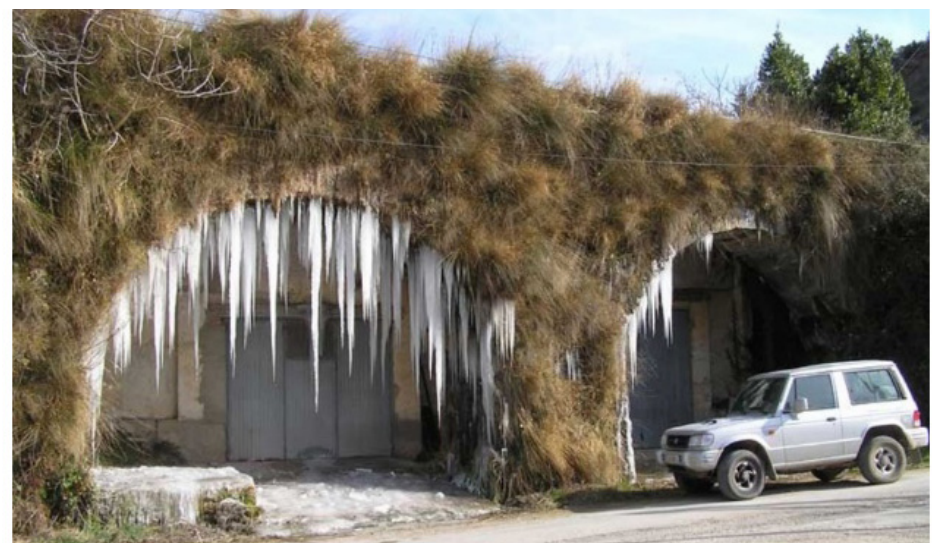

Figura 19. Chupones o carámbanos en Beceite, Teruel.

Foto: Javier de Luna.

Como decimos hay una mayor presencia que en otras estaciones del año de centros de altas presiones, bien el de las Azores o bien otro que nos alcanza desde Centroeuropa. En muchas comarcas aragonesas salvo las del Pirineo, el invierno en general es seco, enero y febrero en particular muestran unos valores pluviométricos similares o incluso más bajos que los de puro verano, otra originalidad más de nuestros climas.

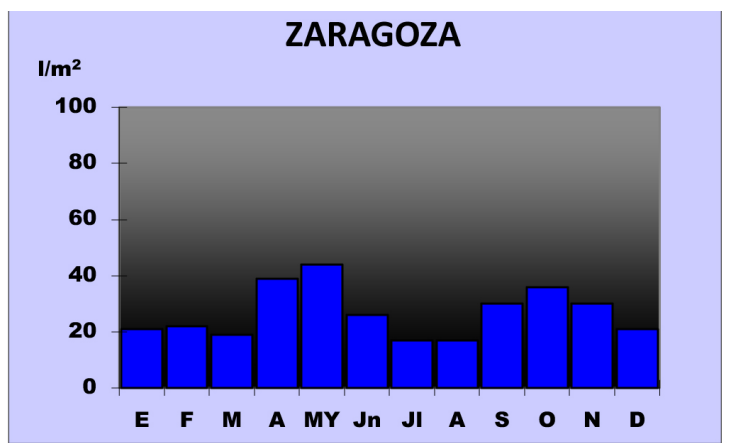

Figura 20. Distribución anual precipitaciones Zaragoza-Aeropuerto (1981-2010).

Fuente: AEMET. Elaboración propia. 
Eso sí con irrupciones rápidas de situaciones del norte que si traen suficiente recorrido marítimo rompen esa monotonía invernal en un mes o en otro pero más en febrero, "si biela en enero, nevará en febrero".

Todos recordamos grandes nevadas en el segundo mes del año aunque este 2021 Filomena invirtió los papeles con una situación más propia de febrero.

"Pa Santa Aguedeta (5 febrero) la nieve hasta la bragueta".

El paso de frentes con su rosario de nubes irán cubriendo el cielo dejando un color característico grisáceo rosáceo que adelanta la nieve: "Cuando el cielo tiene color panza burra nieve segura".

Lo que caiga del cielo será de nieve en zonas altas y medias e incluso en bajas, una nieve siempre bien recibida en el campo y en el monte si no hace daño, por eso son multitud los refranes que reciben con esperanza el elemento blanco que lentamente irá humedeciendo el sustrato.

"Año de nieves, año de bienes", "anno nevoso, anno fructuoso" "anné neigeuse, année fructueuse".

Una nieve que si viene acompañada de viento genera peligrosas ventiscas o "volturnos" en zonas de montaña: "Nieu polbina, mala besina" dicen por el Valle de Benasque.

La oscuridad propia del cielo invernal muchas veces viene determinada por otro meteoro de especial relevancia en nuestra comunidad, especialmente en la Depresión del Ebro. La niebla, la boira, la cegallosa en Fraga abundantes en el "trimestre de las nieblas, noviembre, diciembre y enero, ... favorecidas por situaciones de estabilidad atmosférica ligadas a la presencia de un anticiclón dinámico que se refuerza en los meses invernales, por efecto térmico (Hernández, Mạ . L. 1989)” sin viento o ligero del sudeste.

La niebla condiciona la vida de las personas que viven en esas zonas dejando un ambiente gélido durante todo el día con máximas bajísimas durante varias jornadas y cierta irritabilidad y desánimo en las personas meteorosensibles: "Niebla de sequera, mal tiempo a la Litera", "si vas a Fraga tápate la cara".

Como nieblas de irradiación que son ocupan el fondo de los valles mientras que en zonas medias y altas el sol se impone en las sierras del Pirineo y en las del Sistema Ibérico turolense y zaragozano Días propicios para las tareas en el campo con un tibio sol: "Si ves la niebla en o val coge os güeys y echa a andar".

Esta boira pegada al suelo deja depósitos de cencellada o dorondón, cuando la niebla es engelante creando un paisaje cristalizado que nos recuerda a otras latitudes de nuestro planeta, niebla que se resiente en las horas centrales del día a partir de la se- 
gunda quincena de enero debido a una mayor insolación de un sol tímido todavía pero que consigue romper la inversión térmica y la niebla no dura tanto ya en la Ribera del Ebro y zonas próximas, aunque siguen siendo persistentes en el sur y este de la provincia de Huesca donde además el cierzo no es tan habitual.

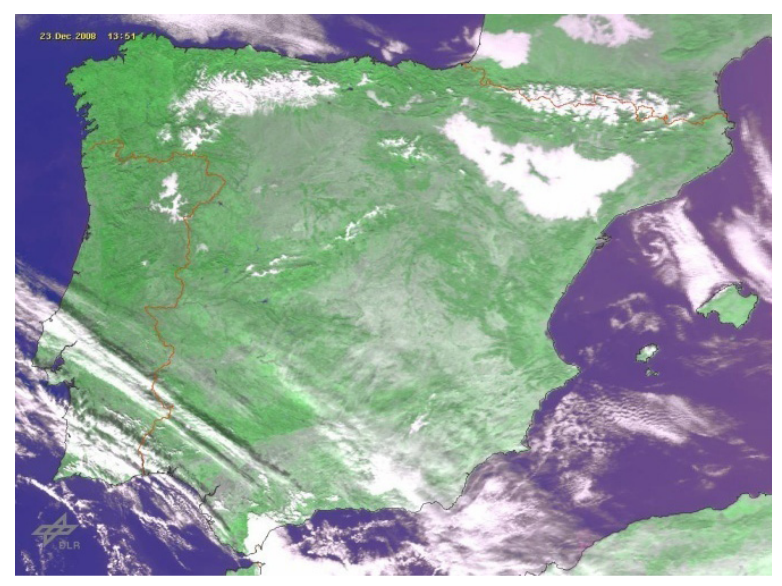

Figura 21. Nieblas ocupando la Depresión del Ebro en invierno. Vista desde satélite.

Fuente: NOAA.

En este sentido tenemos varios refranes: "Para San Antón de enero (17 enero) pierde la boira su aposento" o "ta San Antón la boira no llega a las dos" En febrero con mayor presencia de luz solar las nieblas son mucho menos frecuentes o levantan pronto.

Efectivamente en febrero se nota cierto alivio térmico a pesar de que el retroceso al puro invierno puede ser más que habitual, y en ocasiones protagonizando advecciones polares continentales cuyos registros térmicos han configurado las mayores olas de frío recordadas (febrero 1954 y 1956).

De todas formas que suban las temperaturas pero sin exceso: "si en febrero busca la sombra el perro, mal año para el jornalero" y para los almendros especialmente que acumuladas sus horas de frío necesarias pueden abrir sus flores en las variedades más tempranas a finales de enero con el consiguiente riesgo agrícola: "Si el almendro no se apresurara, la flor no se le helara, que aprenda del moral que tarda más en brotar".

Porque febrero puede presentar matices primaverales, con muchas variaciones incluso en un mismo día que despistan: "Febrero un rato al sol y otro al humero". Esa volubilidad no la perdona el refranero: "febrero cara de perro", "febrero curto e fiero", "febrero loco sacó a su hermano al sol, y luego lo apedreó". 


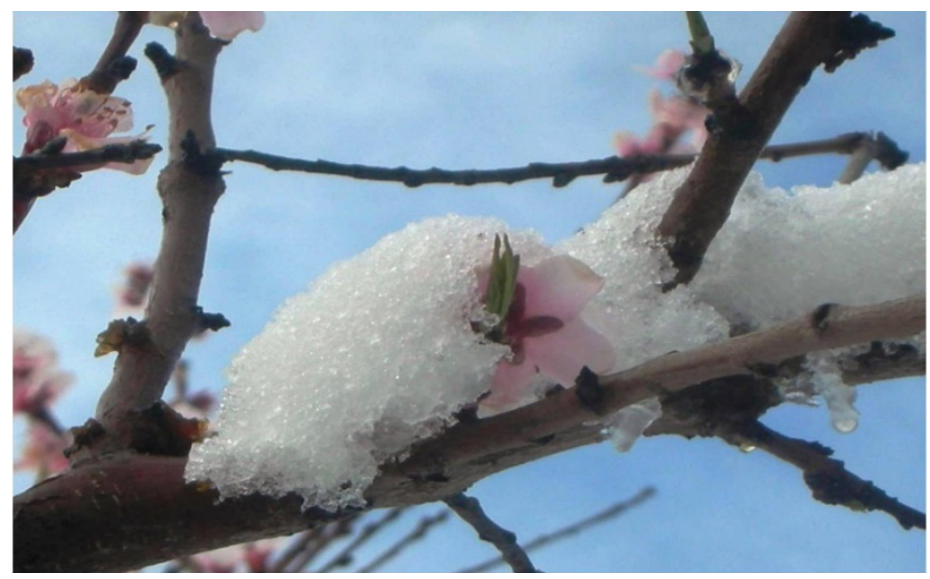

Figura 22. Nevada sobre almendros florecidos en febrero, Morata de Jalón (Zaragoza).

Foto: Carmina Oriol.

El lento despertar de la vida natural comienza a verse retratada también en el refranero: "Ta San Blas a cigüeña verás" aunque ya sabemos que el comportamiento de las cigüeñas ya no sigue las pautas migratorias siendo un ave sedentaria en muchos casos cuyo comportamiento quizás algo tenga que ver con el aumento de temperaturas originadas por el calentamiento global, o con una mayor disponibilidad de comida evitando el flujo migratorio.

Algunas aves ya comienzan a dejarse notar junto a nosotros, "ta Santa Olaria (12 febrero) a burbuta canta", mientras, como ya hemos comentado, las grullas inician su viaje de regreso, y de alguna forma indican que la primavera no está lejos, pero esa es otra estación, y otro ciclo.

Y por último como colofón me gustaría apuntar unos refranes que valoran otros aspectos climáticos de nuestra comunidad y que quizás no hayan quedado reflejados hasta ahora y que por su especificidad y perfecta descripción de los climas de Aragón merecen ser mencionados al menos:

Aragón, nueve meses de invierno, tres de infierno" o la versión pirenaica desde Castejón de Sobrarbe "ocho meses de ibierno, y cuatro de infierno".

"Aragón se incluye dentro del ámbito mediterráneo continentalizado, con inviernos fríos y veranos calurosos y secos" (Cuadrat, 1999, p.7) y una escasa representación de las estaciones equinocciales con nula influencia dulcificadora marina que acorta las estaciones equinocciales como ya hemos tratado y alarga en zonas de montaña los meses invernales donde el verano puede ser muy corto: 
"El verano en la montaña comienza en Santiago (25 julio) y termina en Santa Ana (26 julio)".

Aragón es tierra de contrastes orográficos importantes, desde los poco más de $70 \mathrm{~m}$ de altitud del municipio de Fayón hasta los $3404 \mathrm{~m}$ del Aneto. Tierra de montañas con altitudes elevadas en el norte de la Península Ibérica que permiten hablar de un clima no solo de montaña sino de alta montaña que enriquecen todavía más si cabe la variedad climática que podemos encontrar en una comunidad autónoma de tan solo $47.000 \mathrm{~km}^{2}$.

A partir de los 2500-3000 m de altitud lo podemos considerar así, con los últimos glaciares de nuestro país, y allí y no en otro lugar de Aragón, se encuentran los lugares más fríos de la comunidad, con temperaturas medias bajas y seguramente con valores absolutos de récords aunque la ausencia de datos no nos permiten hablar de cifras concretas. Clima de largo invierno y corto verano que define perfectamente este refrán.

Por último hablar del cierzo en el Valle del Ebro es hablar más que de un elemento climático sin más, es una seña de identidad de toda una comunidad como la nuestra, con efectos positivos en algunos casos (limpia la atmósfera), pero en otras ocasiones no es tan beneficioso, "la velocidad del viento es alta incluso en verano (media 19,4 $\mathrm{km} / \mathrm{h}$ en julio) lo que unido a las altas temperaturas estivales multiplica las necesidades hídricas de las plantas y refuerza los efectos de la sequía veraniega (Hernández, 1990, p. 64) además de los efectos, perjudiciales, fisiológicos y mecánicos que las altas velocidades pueden acarrear".

Los altos valores de evapotranspiración en nuestra comunidad añadidas a las escasas precipitaciones generan un déficit hídrico como en pocas partes de nuestro país.

El refrán es contundente: "El cierzo y la contribución, la ruina de Aragón" que podría ser la versión aragonesa de un refrán de validez general y que implica, además, un juicio de valor: "Con viento nunca es buen tiempo" por todo lo dicho y además por las afecciones que tienen sobre las personas meteorosensibles: "La meteorosensibilidad constituye no solo un fenómeno en el que existen componentes más o menos subjetivas, sino un realidad biológica que se explica mediante las leyes de la psicoquímica y la electrofisiología” (Molina, J.C., 2005, p. 3).

Y ya que hemos introducido un matiz subjetivo en el anterior refrán "buen tiempo" podemos añadir un último refrán con cierto tono socarrón, oído en los Monegros oscenses y zonas próximas que acuña la gente del campo cada vez que el urbanita califica como buen tiempo el tiempo con sol: "Buen tiempo pa fer sal, pa lo demás... muy mal". 


\section{Conclusiones}

Este artículo ha pretendido ir más allá de una labor de "arqueología lingüística" e intentar demostrar con unos cuantos ejemplos la validez descriptiva, explicativa, predictiva, e incluso científica, de un puñado de refranes propios de Aragón o no, pero que pueden contribuir a un mejor conocimiento de los estados del tiempo, las realidades climáticas y sus consecuencias en las actividades humanas y el mundo natural. La sencillez y claridad de estos ripios pueden ser muy válidos para una mejor comprensión de nuestro tiempo y clima en todos los niveles educativos como decíamos al principio contribuyendo además a su conservación y valoración como fuente cultural, social e incluso antropológica.

Unos generales o y otros más particulares, pero teniendo en cuenta siempre que la gran mayoría de los refranes de la temperie tienen la limitación espacial de la gente que lo identificó, muy reducida a veces a su pequeño radio de acción vital. La gran mayoría solo son válidos para la zona en la que fueron creados. Habrá que seleccionar, depurar, incluso refinar, pero, aunque a muchos no se les puede pedir más, lo que dan, no es poco.

\section{Agradecimientos}

Por último, decir que este artículo está dedicado a mi maestro, profesor y ya amigo José María Cuadrat que, con su ilusión impertérrita, sus ganas de trabajar y su ayuda, ha permitido que me ilusione en esta ocasión y en tantas otras, y que ponga palabras, gráficos, mapas, hechos, sabiduría y cientificidad a lo que muchas veces se queda solo en una conversación de ascensor.

Que tengas siempre buen tiempo José María.

\section{Bibliografía}

Aliaga, J.L. (2012). Refranes del Aragón que se fue. Zaragoza: Gara d'Edizions.

Arnal, P. (1953). Refranes, dichos, mazadas... en el Somontano y montaña oscense. Zaragoza: Institución "Fernando el Católico".

Beltrán, F. (2000). Pirineo Aragonés. La Magia del Tiempo. A maxia de l'orache. Zaragoza: Ariel. Cuadrat, J.Ma. (1999). El clima de Aragón. Zaragoza. Colección CAI 100.

De Jaime, J. et al. (2002). Refranero Aragonés Zaragoza. Institución "Fernando El Católico". Damián, J. (2013). Espiga. Refranes agrarios del Alto Aragón. Zaragoza. Comuniter Editorial. Font, I. (2000). Climatología de España y Portugal. Salamanca: Universidad de Salamanca. 
García de Pedraza, L. (1985). La predicción del tiempo en el Valle del Ebro. Madrid: INM.

Hernández, M.L. (1992). Climatología agrícola del valle medio del Ebro. Dpto. Geografía y Ordenación del Territorio. Univ. Zaragoza (tesis doctoral inédita).

Hurtado, L. (2017). La meteorología en los refranes. Madrid. AEMET.

IAEST (2020). Datos Básicos de Aragón 2020. Zaragoza. Gobierno de Aragón.

Ledesma, M. (2000). Climatología y meteorología agrícola. Madrid: Paraninfo.

Lolumo, E., Berlanga, E., Fernández D. (2014). El tiempo y el clima de Aragón al alcance de todos. Zaragoza: Mira Editores.

López, F., Cabrera, M., Cuadrat, J.Ma (2007). Atlas Climático de Aragón. Zaragoza: Dpto. Medio Ambiente. Gobierno de Aragón.

Martín, J. y Olcina. J. (2001). Climas y tiempos de España. Madrid: Alianza Editorial.

Sánchez, J. (1986). El libro de los refranes de la temperie Madrid: INM.

Santamaría, C. (2017). Sapienza en purnas. L’añada en o refranero altoaragonés. Zaragoza: Aladrada Ediciones.

Toharia, M. (1985). Meteorología popular. Madrid: El observatorio ediciones. 
